Jap. J. Pharmacol. 1. $130(1952)$

\title{
LOCOMOTION OF ASCARIS SUILLA ET LUMBRICOIDES AND THE INFLUENCE OF ANTHELMINTHICS UPON THEM
}

\author{
YOSHITO KOBAYASHI, TAKEO BANDO AND TATSUSHI ISHIZAKI
}

Department of Pharmacology, Faculty of Medicine, University of Tokyo

Received for publication December 15, 1951

At the present time, ascariasis is to be considered as one of the serious medical problems in the oriental countries including Japan. In many. human experiments in our country, it is found that both santonin and hexylresorcinol are reliajle in their anthelminthic action (1). From the result of comparable studies on the pharmacological as well as clinical benefits of both drugs, it is confirmed that santonin is markedly superior to the ther in view of its negligible side action. Effective doses of santonin never induce ill effects except a slight and temporary disturbance in vision, while oral administration of hexylresorcinol induced some lucal ircitations on the mucous mambrane of the digestive organ, even when it was administered under a perfec: condition of coating on it. After taking santonin, ascar is are explled alive and active. Some authorities, therefore, assume that santonin is not directly toxic to the pacasites, but that rather they are irritated by the drug and migrate from the small intestine to the colon to be expelled (2-5). According to others, the drug is excreted in the intestine as an unknown compound, possibly an oxidation product, on which the ascaricidal properties may dapend (7-12). But there has been no positive evidence to support both of the views until recently. We have now been able to find out a characteristic locomotion of ascaris in a glass tube which is made to initate the shape of the bowel, and have goxd reasons to connect this movement of the worm closely with the anthelminthic activity of santonin (13).

THE LOCOMOTION OF ASCARIS IN THE GLASS TUBE

To observe the locomotion of Asaris suilla et lumbricoides, we put them into glass tubes filled with Locke-Ringer's solution modified by us ( $\mathrm{pH} 7.0$ ) or Bunge's solution kept at $30-33 \mathrm{C}$. The glass tub 3 must be of an appropriate length and dianjer depending upon the size of tha worm as will be dascribed later in detail. These ace mounted horizontally for observation of motor activities. A characte$r$ istic lacomo:ion hither to unreported resembling somewhat to that of the inchworm was abservad. The warm usually takas the foim of two or three undulatory curvatures in the fore part of the body in the glass tube. Without changing these curvatures, the worm draws its tail forward producing a curvature in its hind part when it starts locomotion. Then, this curvature moves forward while the tail end remains fixed, and the wom pushes the fore part of the body forward in a wave-like motion. The worm can thus move forward by repeating this mo- 
tion beginning with the movement of its hind portion (Palate 1). In addition, the worm can be seen to make continuous movements with its head as if in search of something. Sometimes, it moves backwards or turns and reverses the direction of its progression. When the Ringer's solution or Bunge's solution in the tube is reduced to some extent, the worm always changes its position to keep its whole body immersed in the solution. With regard to the movement of nematoda, we have only a report by Stauffer (14) who observed the locomotion of various species. However, his study of the parasites in the intestine was not very extensive and he assumed only that they would move more irregularly in the intestine. He noticed that nematoda can only bend in the dorso vertral plare, and we have confirmed this in ascaris.

We also observed that in the isolated pig- or rabbit-intestines the motion of pig ascaris was the same as in the glass tube. The following experiments include the studies on (a) the period and velocity of each movement of the worm, (b) the preferable size and shape of the glass tube that is most suited for the locomotion of the worm inside, (c) the optimal temperature of the solution for observation of the locomotion and (d) the change of the movement related with the lapse of time in the solution.

The period of each movement

When the worm moves forward, it makes the curvatures in the hind part of the body which slide forward through the fore part of the body along which two or three curvatures are formed. Thus the locomotion appears to be based on production and transmission of the wave-like curvature of the body.

The period of this movement was measured by recording the time in which one wave-like curvature passed through a given part of the body. The frequency distribution showing the fuctuation of the period of the movement of the worm

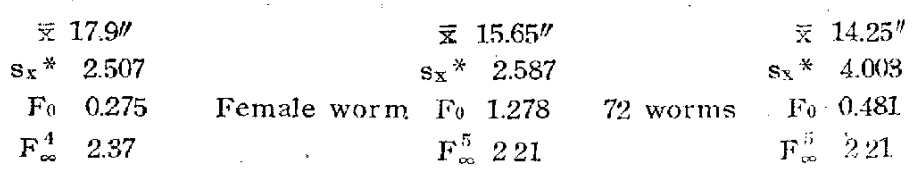
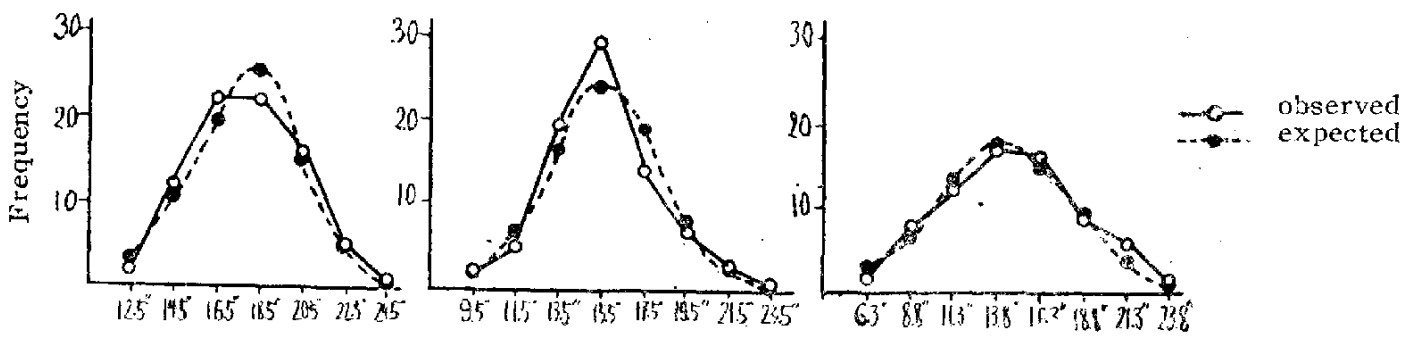

Period in seconds

FIC. 1. Frequency distribution showing the fluctuation of the period of the movement of the worm calculated by Kenney's mathematic of statistics 
TABLE I. Sample mean $(\overrightarrow{\mathrm{x}})$ and mean square $\left(\mathrm{u}^{2}\right)$ of the period of the movement, calculated by Snedecor's statistical method

\begin{tabular}{|c|c|c|r|r|r|}
\hline $\begin{array}{c}\text { Male worms } \\
\text { No. }\end{array}$ & $\overline{\mathrm{x}}$ & $\mathrm{u}^{2}$ & $\begin{array}{r}\text { Female worms } \\
\text { No. }\end{array}$ & \multicolumn{1}{|c|}{$\overline{\mathrm{x}}$} & $\mathrm{u}^{2}$ \\
\hline 1 & 16.5 & 9.88 & $\mathrm{I}$ & 9.8 & 2.62 \\
2 & 16.8 & 12.8 & 2 & 1.8 .4 & 1.82 \\
3 & 13.7 & 4.68 & 3 & 8.1 & 2.99 \\
4 & 8.2 & 1.51 & 4 & 8.3 & 1.68 \\
5 & 18.4 & 5.38 & 5 & 19.7 & 1.34 \\
6 & 12.0 & 8.89 & 6 & 10.1 & 3.27 \\
7 & 22.6 & 10.0 & 7 & 16.1 & 3.21 \\
8 & 15.3 & 8.46 & 8 & 9.8 & 3.07 \\
9 & 21.3 & 5.79 & 9 & 17.3 & 9.79 \\
10 & 17.2 & 12.4 & 10 & 17.0 & 6.56 \\
11 & 12.8 & 5.96 & & & \\
\hline
\end{tabular}

was noted by measurements of the periods of the movements eighty times in two worms respectively, and in a like manner 72 worms were taken and the frequency distribution of the period was measured once at random in each. It was consequently found that they belong consistently to the "normal type" which indicates the stable nature of the movement, if the worm is tested on the day it is extracted from pig bowel (Fig. 1). To ascertain the individual variance in the distribution of the period, experiments were carried out with 21 worms, measurements being taken ten times in each (Table I). These results led us to assume that there was no significant difference in the individuality of the worm notwithstanding the sex difference $(15,16)$.

Ths relationship between the period and the volocity of movement

The worm moves forward at somewhat regular intervals, alternating locomotion and standstill. Comparing the locomotion of the worm on the day it was exposed to the artificial solution with that on the next, little change could be recognized, viz., the duration of the locomotion phase bscame shorter on the next day, although that of the standstill phase remained unchanged on both days (Table II). 
TABLE II. Comparison of the locomotion of the worm on the day it was ex. posed to the solution with that on the next

\begin{tabular}{|c|c|c|c|c|c|}
\hline $\begin{array}{l}\text { Lapse of } \\
\text { time }\end{array}$ & $\begin{array}{c}\text { Worms } \\
\text { No. } \\
\text { - }\end{array}$ & $\begin{array}{l}\text { Time in } \\
\text { which worm } \\
\text { keeps mov- } \\
\text { ing (in mi- } \\
\text { nute) }\end{array}$ & $\begin{array}{l}\text { Time in which } \\
\text { worm stays in } \\
\text { standstill (in } \\
\text { minute) }\end{array}$ & $\begin{array}{l}\text { Period in } \\
\text { seconds }\end{array}$ & $\begin{array}{l}\text { Velocity } \\
\text { in } \frac{\mathrm{cm}}{\mathrm{min}}\end{array}$ \\
\hline \multirow{4}{*}{0} & 1 & 25 & 8 & 25 & $3.5^{*}$ \\
& 2 & 27 & 7 & 27 & 5.0 \\
& 3 & 13 & 10 & 26 & $2.0^{*}$ \\
& 4 & 13 & 18 & 26.5 & 4.5 \\
\hline \multirow{4}{*}{1} & 1 & 13 & 13 & 34 & 1.5 \\
& 2 & 2 & 6 & 28 & $2^{*}$ \\
& 3 & 2 & 8 & 25 & 4.5 \\
& 4 & 5 & 11 & 25 & 4.0 \\
& 5 & 4 & 8 & 26 & 4.0 \\
& 6 & 3 & 10 & 26 & 4.5 \\
\hline
\end{tabular}

* The production of the curvatures of the body was not as complete as in the ordinary locomotion

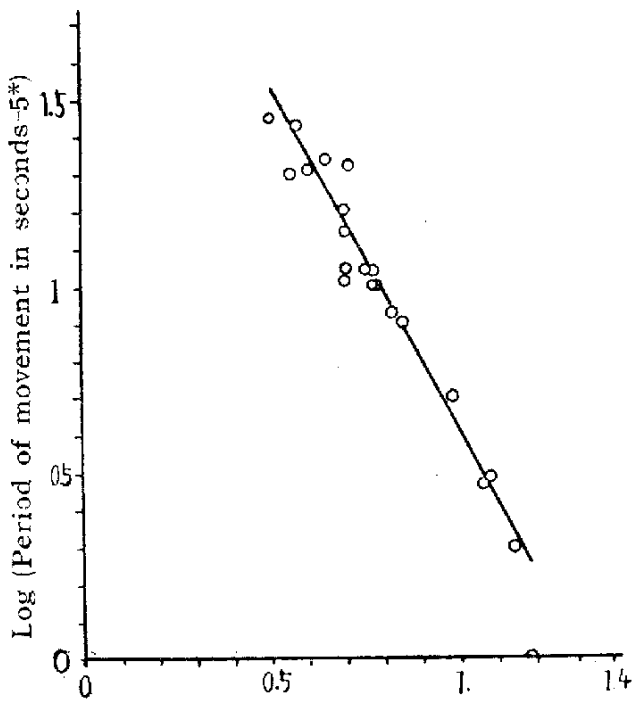

$\log$ (Velocity of movement in $\frac{\mathrm{cm}}{\mathrm{min}}$ )

FIG. 2. Correlation between the period and the velocity of the movement of ascaris in the glass tube

* The minimum period of the movement in all the worms tested, i. e., 5 seconds, is subtracted from the actual period observed.
Generally, the velocity was increased if the period of the movement was shorter. In a few cases, the curvature started in the middle portion of the body instead of its hind part. In such atypical cases, the velocity of the movement was much reduced. So far as the ordinary type of movement is concerned, there is a close relationship between the velocity and the period of the movement which may be expressed by the formula: $X(Y-5)^{1 .}{ }^{* 19}=310.7$, where $\mathrm{X}$ denotes the velocity in $\mathrm{cm} / \mathrm{min}$. and $\mathrm{Y}$ the period in sec. respectively (Fig 2).

The preferable shape of the glass tube in cross-section

Experiments performed hitherto by us were those in the glass tube having a circular cross-section and of $75 \mathrm{~cm}$ in its length. But now various tubes of different cross-sections with a certain 
length, at least longer than the body-length of the worm, were taken to observe the locomotion of the worm in them. In a tube which is square in cross-section, the worm pushed itself along one of the diagonal planes slightly less smoothly than in the round one, if the size of the tube was adequatefor its body-length as will be described later in detail. In an open square tube without the top, the worm appeared to keep on its much slower locomotion along the bottom. It was consequently revealed that ascaris seemed to prefer one of the glass tubes which was made to imitate the shape of the bowel as possible. We believe it must be a reasonable environment for the worm infesting such a particular space as the bowel.

The adequate diameter of the glass tube in relation to the velocity of movements in it

Eight glass tubes of different diameters such as $0.5,0.7,1.0,1.5,2.0,2.5,3.0$ and $3.5 \mathrm{~cm}$, were prepared to test the movement of the worm in each of them. With the exception of the tubes which are too small, or too large, in their dia-

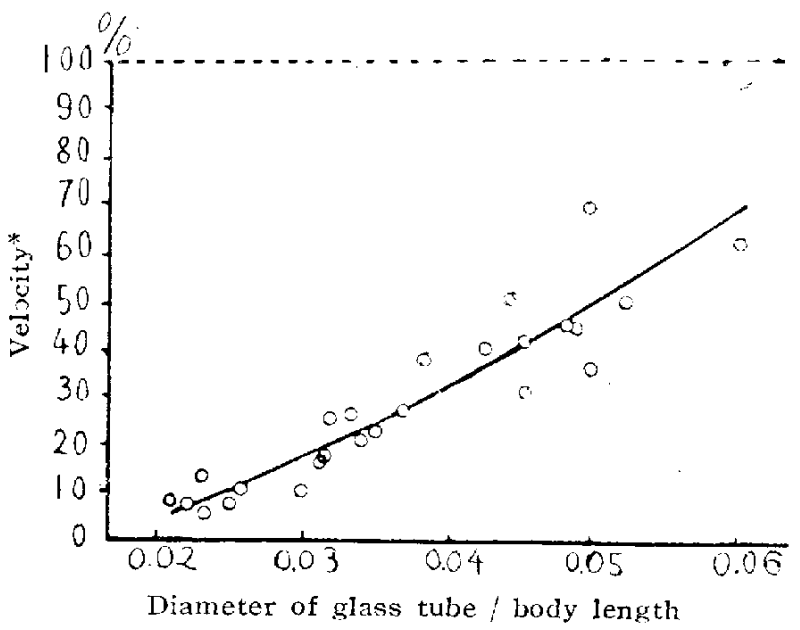

FIC. 3. Correlation between the velocity and the ratio of the diameter of the glass tube to the body length

* Relative velocity calculated in percentage of the highest one. meters in order to produce thrce or four proper curvatures on the worm body necessary for its motor activity, the worm happened to change the velocity of the movement to some extent, while the period of the movement did not vary so distinctly in each of the glass tubes of different diameters. It was found that there was a relation between the diameter of the glass tube or, to be more precise, the ratio of the diameter to the body-length and the velocity of the movement (Fig. 3). Each of 45 worms with various body-lengths was put

into one of the glass tubes of different diameters, and a total of 144 observations on the velocity of the movement was made in order to find out the relation of the ratio between diameter and body-length to the number of worms showing the value of 100 per cent, i. e., the highest velocity among all tested. Although the range of the ratio between diameter and body-length which is necessary to have the highest value in the velocity varied more or less in each worm, yet some connection could be recognized by these experiments. It was clarified that most of the worms, about 90 per cent of those tested, were able to move livelily forWard in the glass tubes whose diameters lay between 1/11 - 1/16 of their body- 
lengths (Fig. 4).

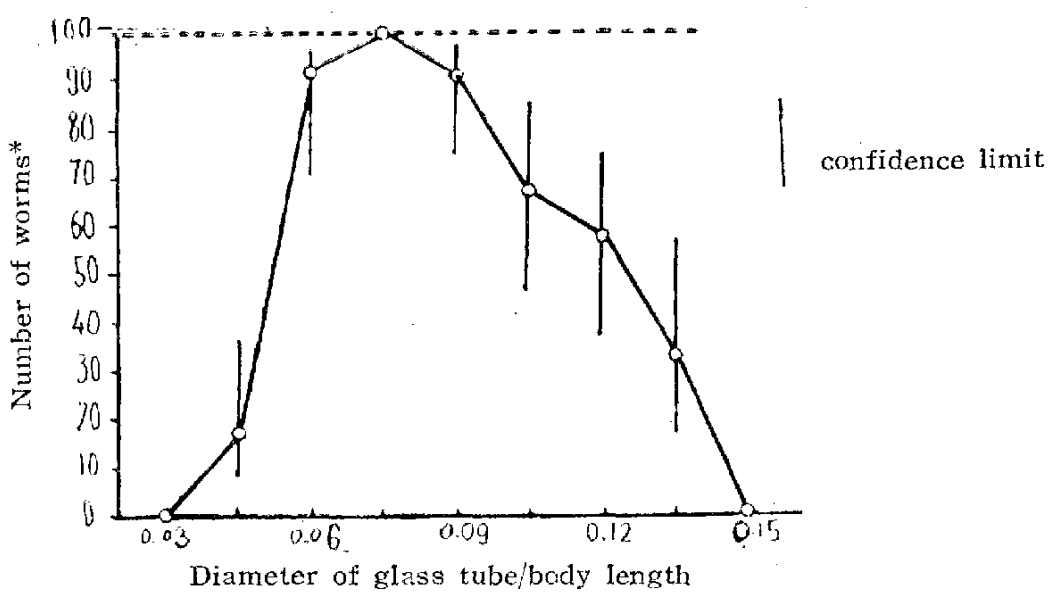

FIs. 4. The range of ratio between the diameter of the glass tube and the body length in relation to the number of worms showing the highest velocity in it

* Number of worms indicating the highest velocity in percentage of all the worms tested.

The motor activity of the worm in relation to the lapse of time in the solution

The locomotion of the worm became less active with the lapse of time in the artificial solution in the glass tube. The results obtained by 16 worms indicated that the length of time during which the worm could move forward was 184.8 hours in average. And, in close relation to the lapse of time in the solution, there was some prolongation in the period of each movement as well as in the length of time during which the worm remained in standstill (Fig. 5).

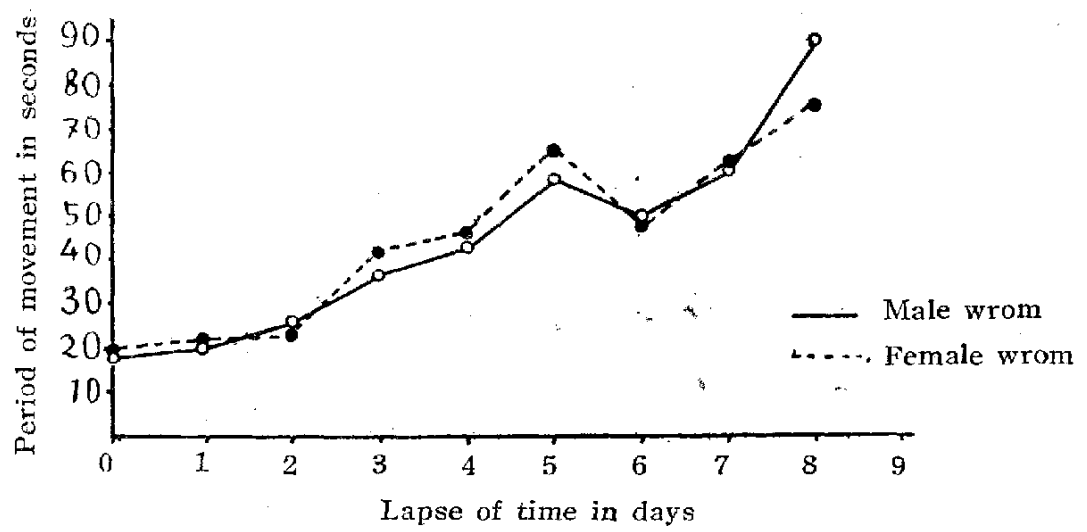

FIG. 5. Change in the period of the movement in relation to the lapse of time in the solution 
Statistically speaking, no significant differerce was recognized between the period of the movement measured on the day when the worm was taken out of the pig bowel and that on the next day; from the third day on, however, there was some significant difference (17). Generally, the initial period of the movement was maintained within about 30 hours after exposure to the solution. But, when the worms showing distinct motor activities were picked out at random to be kept under observation for about two hours everyday, in order to know how many worms indicated locomotion, the result differed slightly from the one described above (Table W). It may be, therefore, concluded that the initial locomotion

TABLE III. The diminution of the number of worms showing their locomotion in the lapse of time

\begin{tabular}{|c|c|c|c|c|c|c|c|c|}
\hline $\begin{array}{l}\text { Lapse of } \\
\text { time in } \\
\text { days }\end{array}$ & 0 & 1 & 2 & $\mathbf{3}$ & 4 & 5 & 6 & 7 \\
\hline $\begin{array}{l}\text { Locomo. } \\
\text { tion }\end{array}$ & 8 & 3 & 2 & 1 & $I$ & 1 & 0 & 0 \\
\hline Standstill & 0 & 5 & 6 & 7 & 7 & 7 & 7 & 7 \\
\hline $\begin{array}{l}\text { Period in } \\
\text { seconds in } \\
\text { locomotion }\end{array}$ & 15.6 & 20.0 & 282 & 97.8 & 43.8 & 61.8 & 46.9 & 60.1 \\
\hline
\end{tabular}

of the worm is observed only on the first day of the test, viz., during about 10 hours after the exposure to the fluid environment adopted by us in the present experiment.

The length of survival of the worm in the solution was found to be 273.6 hours in average of 16 worms. From the statistical studies as to the relation between the length of survival and the duration of maintaining the lively locomotion, as well as the relation between the latter and the period of each movement, no significant results were obtained.

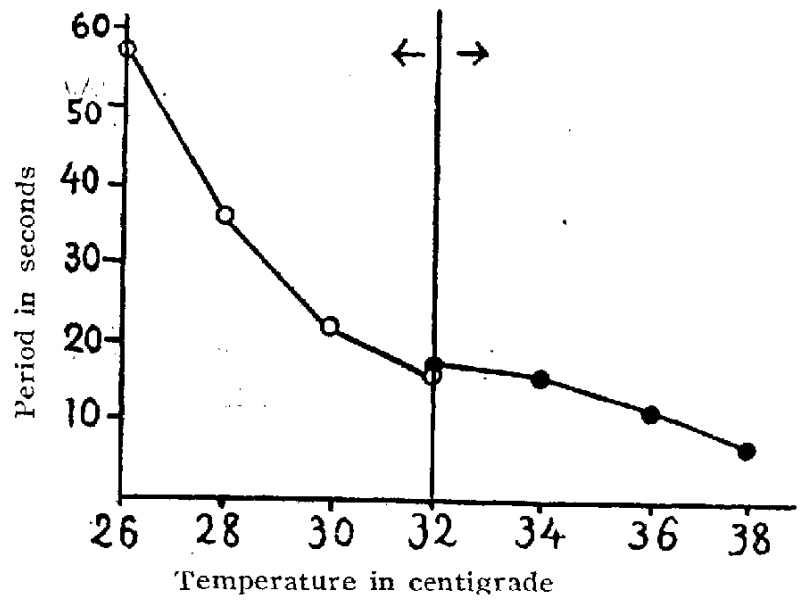

FIG. 6. The period of the movement influenced by the change in the temperature of the solu. tion in which it was tested
Influence of the temperature upon the locomotion of ascaris

The period of the movement ot ascaris was markedly influenced by the change in the temperature of the solution in which it was tested. If the temperature was raised, the period became shorter generally. But there was no significant difference between $32^{\circ} \mathrm{C}$ and $34^{\circ} \mathrm{C}$, whereas differences between those and some other temperatures were signifcant (Fig. 6). It was also found 
that the number of worms keeping on their locomotion was highest in the solution maintained at $32^{\circ} \mathrm{C}$, when the temperature of the solution was raised as well as lowered gradually in a wide range, and that it became less and less, when the temperature was set further and further from $32^{\circ} \mathrm{C}$.

Several abnormal movements and postures of the worm-body took place in the temperature range of $20^{\circ} \mathrm{C}$ to $50^{\circ} \mathrm{C}$. (1) Searching movement of the head. The worm can be seen to make continuous movements with its head as if in search of something as described above. This is more distinct during the period in standstill rather than in locomotion, especially in the solution maintained at a temperature near optimal. But this searching movement became more marked and severe when the environment for the worm was abnormally high in temperature. When the tip of the head of the worm, in which its central nervous organ is localized, was removed, the searching movement of the head could no longer be observed, but the worm continued the same locomotion (Table IV). This movement of the

IABLE IV. The period and the velocity of the movement of the worm before and after deprivation of its central nervous organ

\begin{tabular}{|c|c|c|c|c|c|}
\hline \multirow{2}{*}{$\begin{array}{l}\text { Worms } \\
\text { No. }\end{array}$} & \multirow{2}{*}{ Sex } & \multicolumn{2}{|r|}{ Before } & \multicolumn{2}{|r|}{ After* } \\
\hline & & $\begin{array}{l}\text { Period in } \\
\text { seconds }\end{array}$ & Velocity in $\frac{\mathrm{cm}}{\mathrm{min}}$ & $\begin{array}{l}\text { Period in } \\
\text { seconds }\end{array}$ & Velocity in $\frac{\mathrm{cm}}{\mathrm{min}}$ \\
\hline 1 & $\widehat{s}$ & 7. & 12 & 7.5 & 10. \\
\hline 2 & $\widehat{b}$ & 7.6 & 8. & 7.3 & 8. \\
\hline 3 & $\hat{0}$ & 10.3 & 5.2 & 10. & 5.8 \\
\hline 4 & $\widehat{\delta}$ & 1.2 & 5.5 & 14. & 5. \\
\hline 5 & - + . & 13.3 & 4.8 & 14. & 4.5 \\
\hline 6 & 우 & 13.3 & 6.2 & 13. & 6. \\
\hline 7 & 오 & 16. & 4.5 & 16. & 4.5 \\
\hline 8 & 우 & 18.5 & $4:$ & 20. & 3.5 \\
\hline 9 & 우 & 18.3 & 4. & 19.6 & 4. \\
\hline
\end{tabular}

The temperature of the solution was maintained at $32 \mathrm{C}$ throughout observation *No searching movements of the head of the worm.

head of the worm must be, therefore, one of the normal motor activities presumably necessary for the worm to push itself forwards without difficulty. (2) Backward movement. The worm moved backwards and reversed the direction of its progression with the initial curvature starting in the fore part of the body. But the production of curvatures of the body was not as complete as in the ordinary movement and the velocity was so low that it may be inadequate to regard it as a proper retrograde locomotion of ascaris. This could be seen in the solution at such abnormally high temperatures as from $36^{\circ} \mathrm{C}$ to $46^{\circ} \mathrm{C}$. (3) Shape of the

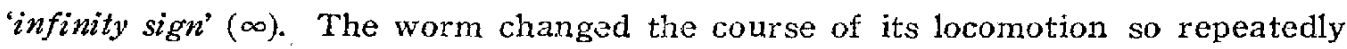
that it took the shape of an infinity sign $(\infty)$. This came often in sight in the 
solution at cvery temperature above $30^{\circ} \mathrm{C}$. (4) Shape of a coil. The worm curled itselt somewhat regularly just as a coil of wire. This appeared in the solution at abnormally high as well as low temperatures. (5) Sirething the whole body in a standstill. The worm stretched itself motionless when it was extremely low in vitality near the end of life in a most unsuitable environment. (6) Shivering at the head. This appeared distinctly only at its head in the case of temperature higher than $40^{\circ} \mathrm{C}$.

Each of such postures or movements, except the searching movement of the head, differentiated from the origninal one was shown in a certain range of temperature of the fluid environment which was changed. But the worm showed at last the normal type of the locomotion with a much longer period than that of the original one, indicating a decrease in vitality, after it had gone through several abnormal movements under a relatively high temperature maintained throughout the observation. The highest and lowest temperatures of the solution in which few worms could move to some extent were $50^{\circ} \mathrm{C}$ and $20^{\circ} \mathrm{C}$ respectively. However, all the worms were killed in a moment when they were put

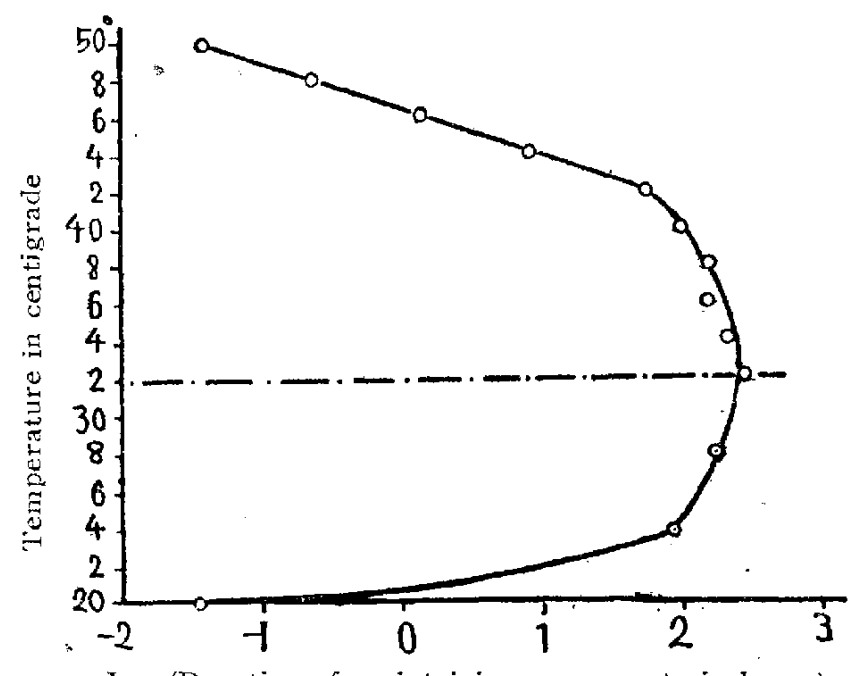

Log (Duration of maintaining movements in hours)

FIC. 7. The time-interval from the beginning of the test until the worm showed no spontaneous movement at various temperatures of the solution

into the solution of $60^{\circ} \mathrm{C}$. Female worms were a little more resistant to the higher temperature; on the contrary, male ones tolerated the lower temperature as a rule. The time-interval from the beginning of the test until the worm ceased completely its movement, was measured in the solution of various temperatures (Fig. 7). As far as observed by us, it was longest at $32^{\circ} \mathrm{C}$, and became shorter at any other temperature higher or lower. When the central nervous organ of the 
worm was cut away, the influence of the temperature upon the locomotion did not happen to be observed. It is therefore concluded that the part of the body most sensible to the temperature may be identified as the central nervous organ contained in its head, and that the optimal temperature of the solution for our experiments concerning the locomotion of ascaris is $32^{\circ} \mathrm{C}$.

\section{DISTURBANCE OF LOCOMOTION BY SAN TONIN AND SOME OTHER DRUGS}

The results of experiments described above led us to consider that it must be quite reasonable to explore the influence of the drug such as santonin, whose anthelminthic efficacy was still obscure in its mode of action upon the locomotion of the worm. Atter being confirmed that the worm moved forward in the solu. tion in the glass tube under most suitable conditions as described above, the worm was exposed to the santonin solution in $1: 5,000$ difution maintained as exactly at tho same temperature as before. Whereupon the locomotion of the worm, including the searching movernent of its head, immediately ceased entirely, and then, after a while, its body began to curl around itself. This curling motion takes place in the fore part at first and finally involves the whole body (Plate 2). It remains alive in this condition, but is unable to resume normal locomotion which was present before being placed in the santonin solution. We have termed this condition a "glomerulus-form", bəca'se it resembles, more or lass, the shape of a coil of blood-vessels in the glomeculus. O.l caceful osservation, we noticed that tine movement, which is usually very smosth under normal conditions, was then of a clonic nasure. The resultant effect of santonin on two kinds of worms, viz., As aris suilla et lumbricoides, showed no appreciable difference between them. This suggests that santonin acts as a convulsant drug on the invertebrate such as the nematoda as it does on the vertabrate. Then, the experiments were carried out with other convulsant diugs such as picrotoxin, hetrazan (18-21) and strychnine, and again it was found that these drugs in $1: 5,000$ dilution caused also the disapperanca of the locomotion of the worm and made it curl around the body.

On severing 5-10 $\mathrm{mm}$ of the tip of the head, which contains a kind of central nervous organ of the worm, the curling of the body grew noticeably weaker or ceased entirely in the solution of santonin and picrotoxin. This took place regardless of whether the head was ramoved before or after exposure to them. But in the casas of hesazan and strychnine, there was almost no change in such ab. normal posture of the body aiter cutting off its head.

The results of these tests led us to believe it was assured that the effect caused by santonin represents convulsions of the ascaris. In the vertebrate, the convulsions induced by santonin are regarded as arising from stimulation of the cortex. 'Thus, the higher areas of the necvous system constitute the seat of the action of santonin in both the vartebrate and invartabrate. Susceptibility of the 
nervous system to santonin is, we think, much greater in ascaris than in its host. Thus, the worms infesting the intestine are driven helplessly under the influence of santonin from the small intestine to the colon whence they are expelled. The minimal effective concentration of santonin on Ascaris suilla was determined. In 1:5,000 solution, distinct disturbances of Jocomotion as described above were produced; but in higher concentrations, it did not become more intense as would be expected, probably due to the insolubility of santonin.

TABLE V. Effective concentrations of santonin on Ascaris suilla in the glass tube

\begin{tabular}{|c|c|c|c|c|c|c|}
\hline \multirow{2}{*}{$\begin{array}{l}\text { concen- } \\
\text { tration }\end{array}$} & \multirow{2}{*}{$\begin{array}{l}\text { No. of } \\
\text { ascaris }\end{array}$} & \multicolumn{3}{|c|}{$\begin{array}{l}\text { No. of ascaris curled } \\
\text { around themselves }\end{array}$} & \multirow{2}{*}{$\begin{array}{l}\text { No. of ascaris } \\
\text { discontiuned } \\
\text { their search- } \\
\text { ing movement }\end{array}$} & \multirow{2}{*}{$\begin{array}{l}\text { No. of asceris } \\
\text { discontinued } \\
\text { their locomo- } \\
\text { tion }\end{array}$} \\
\hline & & marked & moderate & mild & & \\
\hline $5 \times 10^{4}$ & 6 & 6 & 0 & 0 & 6 & 6 \\
\hline $2 \times 10^{-4}$ & 13 & 12 & 1 & 0 & 13 & 13 \\
\hline $10^{-4}$ & 11 & 5 & 3 & 2 & 11 & 11 \\
\hline $10-5$ & 10 & 0 & 5 & 3 & 10 & 9 \\
\hline $10-a$ & 15 & 0 & 1 & 1 & 15 & 12 \\
\hline $10^{-7}$ & 10 & 0 & 0 & 1 & 6 & 7 \\
\hline $10-8$ & 10 & 0 & 0 & 1 & 5 & 6 \\
\hline $10^{-9}$ & 6 & 0 & 1. & 2 & 0 & 6 \\
\hline $10^{-10}$ & 10 & 0 & 0 & 2 & 0 & 5 \\
\hline $10^{-1.1}$ & 6 & 0 & 0 & 0 & 0 & 3 \\
\hline $10-12$ & 10 & 0 & 0 & 0 & 0 & 3 \\
\hline $10^{-13}$ & 10 & 0 & 0 & 0 & 0 & 0 \\
\hline
\end{tabular}

In 1 : 100,000-10,000,000 solutions, mild curling occurred, but in lower concentrations, scarcely any effect was evident except for slight disturbance of the normal locomotion. An extremely low concentration, such as 1 : 10,000,000,000,000 solution, produced no effect (Table $V$ ).

It was noted that the time taken to produce the convulsion was found greater in the male than in the female, and that, with respect to the body length, the longer the body the longer it took for the reaction to take plac a (Table VI). 
TABEL VI. Difterence in the action of santonin according to sex and body iength of the worm

\begin{tabular}{|c|c|c|c|c|c|c|c|}
\hline & \multicolumn{4}{|c|}{ Ascaris suilla, female } & \multicolumn{3}{|c|}{ Ascaris suilla, male } \\
\hline $\begin{array}{l}\text { Length of body } \\
(\text { in } \mathrm{cm})\end{array}$ & \multicolumn{2}{|c|}{30} & 20 & $15-12$ & 25 & 20 & $15-12$ \\
\hline \multirow{8}{*}{$\begin{array}{l}\text { Time required for } \\
\text { development of } \\
\text { marked convul. } \\
\text { sions (in minutes) }\end{array}$} & 20 & 12 & 8 & 6 & 119 & $263(5)$ & 9 \\
\hline & 17 & 25 & 15 & 14 & $98(25)$ & $49(9)$ & 11. \\
\hline & 35 & 15 & 11 & 3 & 97 (19) & $261(17)$ & 12 \\
\hline & 121 & 22 & 10 & & & $27(4)$ & 6 \\
\hline & 54 & 10 & 32 & & & $1 \mathrm{LI}$ & 11 \\
\hline & 34 & 110 & & & & 35 & 5 \\
\hline & 13 & & & & & 98 & 5 \\
\hline & & & & & & 79 & \\
\hline Average & \multicolumn{2}{|c|}{37.5} & 15.2 & 7.6 & 104.6 & 115.3 & 8.4 \\
\hline
\end{tabular}

( ): The required for development of mild convulsions (in minutes).

\section{DISCUSSION AND SUMMARY}

For purpose of examination of the anthelminthic action of some compounds, usually a simple procedure was used hicherto by which only the parasiticidal properties of them could be determined. However, no positive evidence was obtained about the activity of such a drug as santonin which did not cause any change in the survival of ascaris in vitro. Since years, our experiments were undertaken to reveal in more detail the life of the parasite in the bowel, and now, a hitherto unrecorded mode of locomotion of ascaris was observed by us in a glass tube which was made to imitate the shape of the bowel. The locomotion was characterized by a dorso-ventral bending and stretching of the body, making a curvature on the hind portion of the body and then sliding the body forward in a wave-like motion through the two or three curvatures on the fore portion of it. In order to push the body forwards smoothly, it seems to be absolutely necessary to produce such curvatures on the body by which the worm attaches to and then detaches from the inner suriace of the glass tube repeatedly. The period and velocity of a wave-like movament were measured in many cases, and it was found that this movement belongs statistically to the "normal type" which indicates the stable nature, and there is also a close relationship between the velocity and the period of the movement. The period of the movement was markedly influenced by the change in temperature of the solution in which it was tested, and the optimal temperature of the solution for experiments concerning the locomotion of ascaris in vitro was found to be $32 \mathrm{C}$. The velocity varies by changing the ratio of the diameter of the glass tube to the body length of the worm. The optimal velocity was obtained when this ratio was set between $1 / 11$ and $1 / 16$. Generally, the initial period of the movement of the worm was maintained within about 30 hours after being tak en out of the pig bowel, while the initial velocity 
of it was observed only during about 10 hours of exposure to the artificial solution.

This typical locomotion caases in the presence of santonin, and the body begins to curl around itself, starting from the fore part and involving the entire body finally. The movement is spasmodic.

With the tip of the head removed, it still continues to wriggle forward with the normal movement, except for the searching movements of the head, characieristic of the unpoisoned worm. In the absence of the head, however, santonin shows practically no effect upon locomotion of the worm.

The santonin-induced spasmodic curling of the body of this species of nematoda may be rogarded as a kind of convulsion in invertebrates. The convulsion seems to be caused mainly by stimulation of the highest area of the nervous system. It is concluded that santonin, when administered to man, causes spasmodic convulsions in Aszaris lumbricoides infesting the bowel, and these motionless worms will ba diven down by the peristalic movements of small intestine and colon to be expelled finally. Sill there remains anothe: problem concerning the activity of this drug which might possibly be excreted into the bowel as an unknown compound atter absorption into the body, and this will be discussed in the next reports.

\section{REFERENCES}

1) LAMSON, P. D.: J. Pharma:ol. \& Exper. Therap. 53, 198, 218 and 227 (19:5).

2) FALCH, C.: Tages Berichte für die Forischritte der Notur-u. Heilkunde. Abi. für. Hyg. u. Phxrmakol. Nr. 49.1, 341 and Nr. 555, 381 (1852).

3) Von Scirrokder, W.: Arch. exper. Path. u. Phrrmakol. 19, 290 (1885).

4) Coppola: Arch. per le science Mediche 11, 255 (1887).

5) Straub, W. And Wedekind, E.: Arch. Phirmazie 244, 623 (1906).

6) TRendelenburg, P.: A.ch. exper. Puth. 4. Pharmakol. 79, 193 (19l6).

7) OGATA, K.: Tokyo Igakkwai Zasshi 33, 1165 (1919).

8) MIURA, K.: Nippon Naikagaku Zasshi 7, 1 (1919).

9) TAKAKAME, Y. AND ASADA, Z.: Okayama Igakkw.i Zasshi No. 400, 355 (1923).

10) KAто, K. Nippon Shokakibyo-gukkwai Zasshi 27, 9 (1928).

1.1) ITo, S.: Keio-I gaku 12, 2053 (1932); 13, 73 (1933).

12) ShIRANE, A.: Tokyo Igakkwai Zasshi 53, 718 (1939).

13) Kobayashi, Y. AND Bando, T.: proc. Japzn Academy 26, 72 (1950).

14) STAUEFER, It.: Zoslogische Jahrbiichy. Abt. für System, Geograph. u. Biol. d. Tiere 49, 1 (1925).

15) KENNEY, J. F.: Muthematics of Statistics 164 (1939).

16) SNEDECOR, G. W.: Statistical Mcihods 206 (1940).

17) SNEDECOR, G. W.: Ibid. 179 (19:10).

18) Hewitt, R. J., Wallace, W., White, E. and Subbarow, Y.: J. Paraasitol. 31, 297 (1948)-

19) Leon, A. And Kanegis, D. V. M.: J. Am. Veterin. Med. Ass. 113, 579 (1948). 
20) Oliver-gonzalez, G., Santiago-Stevenson, D. and HewitT, R. I.: Southern Med. I. L. 65 (1949).

21) HARNED, B. K. et al.: J. Lab. Clin. Med. 33, 216 (1948).

\section{EXPLANATION OF PLATES}

PLATE 1. Normal locomotion of Ascaris suilla in a glass tube filled with the LockeRinger's solution

A) Beginning of observation, Ascaris suilla, female, body length $28 \mathrm{~cm}$, diameter of the tube $2.3 \mathrm{~cm}$.

B) and C) 15 and 27 seconds later respectively.

PLA'TE 2. Ascaris suilla in a glass tube filled with the santonin solution, Ascaris suilla, male, body length: $25 \mathrm{~cm}$; diameter of the tube $2.3 \mathrm{~cm} . \mathrm{A}$ ), B) and C) $17,133,1440$ minutes respectively after the Locke-Ringer's solution being replaced with the santonin solution $(1: 5,000)$. The curling motion takes place at first in the fore part and finally involves the whole body. 
A

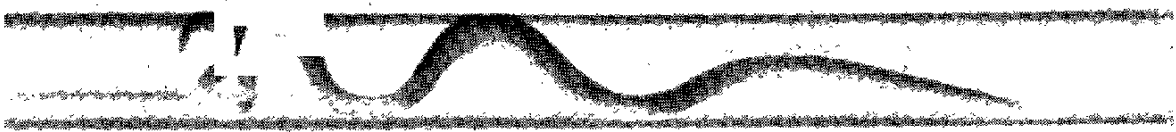

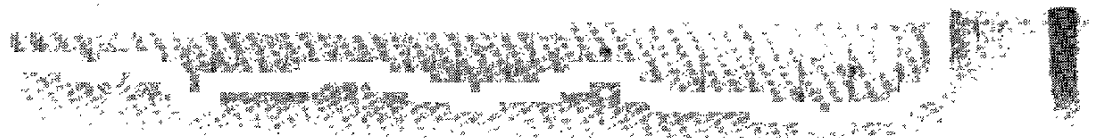

下

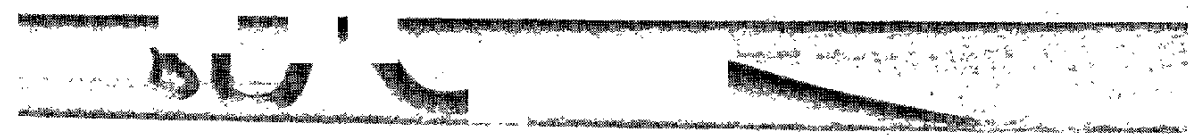

1
4

C

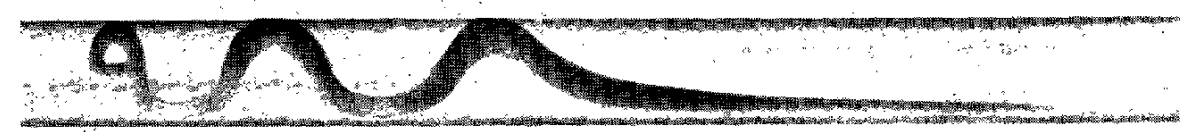

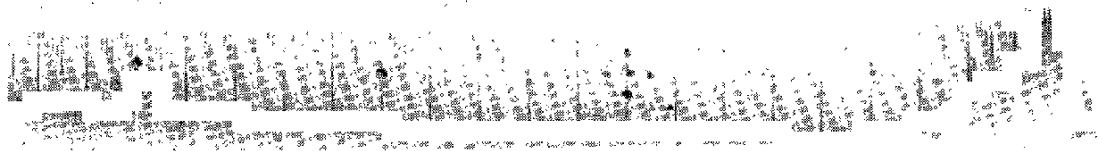




\section{PLATE 2}

Jap. J. Pharmacol. Vol. I, No.2

A

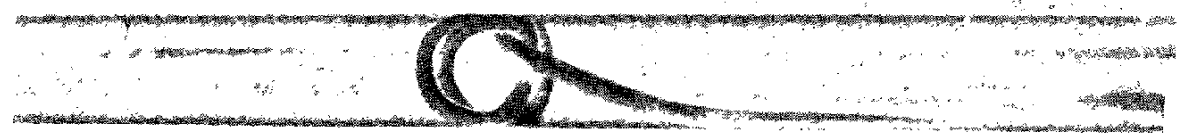

B

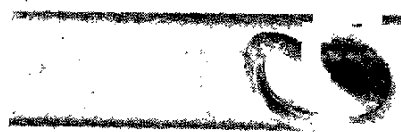

5

-

C
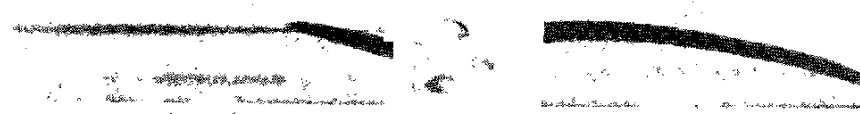

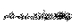

